\title{
CONTROL OF WATER ABSORPTION BY PURIFICATION OF GRAPHITE*
}

\author{
J.E. Simpkins, R.A. Strehlow, P.K. Mioduszewski and T. Uckan
}

Oak Ridge National Laboratory, Oak Ridge Tennessee 37831, U.S.A.

It is well known that graphite can absorb large quantities of water, which can represent an abundant source of oxygen impurities in fusion plasmas if the corresponding components are not properly outgassed. We have outgassed various fusion-relevant graphites (e.g., POCO AXF-5Q) for $1.5 \mathrm{~h}$ at $1500^{\circ} \mathrm{C}$ to release absorbed water and have subsequently exposed the samples to air for various periods of time. Re-absorption of water during the air exposure was estimated by measuring the amount of water produced in subsequent outgassing runs. The results show that the amount of water re-absorbed increases by a factor of approximately 10 within $8 \mathrm{~h}$ compared to the sample in the outgassed state but with no air exposure. The water content of the 'as received' material is reached after approximately 30 days. Re-absorption of water was significantly reduced by $f$ urification of the investigated graphite samples. This purification process, which consists of heating the sample at $2800^{\circ} \mathrm{C}$ for $30 \mathrm{~min}$ in an argon atmosphere, reduces the levels of trace impurities which can be responsible for catalytic surface reactions on the internal surfaces of the graphite. After exposing an outgassed sample to an electron cyclotron heated plasma followed by $1 \mathrm{~h}$ air exposure, the amount of water desorbed was observed to increase by a factor of 6 . Data will be presented to correlate this effect with trace impurities.

\section{Introduction}

Graphite has found extensive use as a plasma-side material in fusion experiments [1-3]. A disadvantage to its use, however, can be its behavior in vacuum. For example, large quantities of water absorbed on the inner surfaces of graphite must be outgassed to minimize this source of oxygen, which contaminates the plasma. In this work, we compare the quantities of the most abundant gases desorbed from various fusion-relevant graphites by subjecting each sample to a carefully controlled thermal

"Research sponsored by the Office of Fusion Energy, U.S. Department of Energy, under contract DE-AC05-840R21400, with Martin Marietta Energy Systems, Inc. 
desorption cycle. These graphites include: (1) POCO AFX-5QB, a standard material graphitized at $2500^{\circ} \mathrm{C}$, manufactured by Union 76; (2) Pyrolitic, a high- temperature material, manufactured by Pfizer Minerals; (3) Stackpole-2020, fine grain, high-strength, specialty graphite manufactured by Stackpole Carbon Co.; (4) CL 5890 PT manufactured by Carbone Lorraine, and (5) a 2-d carbon-carbon composite, manufactured by Goodyear for Princeton Plasma Physics Laboratory.

We show a relationship between outgassing and trace impurities and describe a purification process that not only improves outgassing behavior by lowering the impurity content of the graphite but also lengthens the re-contamination time. We also found that the quantity of desorbed water increased after exposure of un-treated graphite to plasma, but we found no significant increase in outgassing from the purified graphite.

\section{Experimental Procedure}

The outgassing facility used in these experiments has been described in detail elsewhere [4]. The samples were inductively heated with RF power to minimize the heating of other components in the UHV chamber. Other heating techniques have also been successfully employed, for example, heating the sample by radiation [5]. In addition, the walls were kept at $100^{\circ} \mathrm{C}$ throughout the run. A residual gas analyzer (RGA), which was calibrated before each run with test gases, measured the partial pressures of the gases as they evolved. A thermocouple measured the sample temperature and was connected to a microprocessor unit, which controlled the RF power supply. The entire experiment was under computer control; a complete set of data was taken every $20 \mathrm{~s}$. The specimens were machined from graphite stock to form cylinders $2 \mathrm{~cm}$ in diameter and $4 \mathrm{~cm}$ in length. Carbide tools were used to avoid the possibility of adding metallic impurities, and the specimens were handled only with gloves; no other cleaning procedure was employed.

In preparation for a (typical) thermal desorption cycle, a sample was mounted on the thermocouple, which also served as its support, the vacuum system was pumped down, and the vessel walls were baked overnight at $150^{\circ} \mathrm{C}$. The wall temperature was then reduced to $100^{\circ} \mathrm{C}$, the RGA was calibrated, and data acquisition was begun. Typically, a sample was heated from 50 to $1500^{\circ} \mathrm{C}\left( \pm 2^{\circ} \mathrm{C}\right)$ in a 1 -hr linear ramp and held at this temperature for $1.5 \mathrm{~h}$.

The Plasma-Materials Interaction Test Facility (PMITF) [6] was 
utilized for the plasma exposures of the samples. The exposures were made in a deuterium plasma having a density of $10^{11}$ particles $/ \mathrm{cm}^{3}$ and electron temperatures of $15 \mathrm{eV}$. The samples were biased at $-150 \mathrm{~V}$; each total fluence was $10^{20}$ particles $/ \mathrm{cm}^{2}$.

\section{Results and Discussion}

The total amounts of the most abundarit gases which evolved during the initial thermal desorption cycles are shown in Table 1 in units of $\mathrm{Pa}-\mathrm{l} / \mathrm{g}$. These samples received no prior cleaning and were given the same heat treatment during each thermal desorption cycle. The quantity of evolved gas varied among the samples listed. There were also variations between samples prepared from different billets of the same material grade and even between samples from the same billet. Therefore, wherever applicable, the same sample was re-used.

Table 1. Total amounts of gases desorbed from 'as received' samples. $(\mathrm{Pa}-1 / \mathrm{g})$

\begin{tabular}{cccccc} 
Gas & POCO & $\begin{array}{l}\text { Pyro- } \\
\text { litic }\end{array}$ & $\begin{array}{l}\text { Stack- } \\
\text { pole }\end{array}$ & $\begin{array}{l}\text { Carbone } \\
\text { Lorraine }\end{array}$ & $\begin{array}{c}\text { carbon-carbon } \\
\text { composite }\end{array}$ \\
\hline $\mathrm{H}_{2}$ & 19.95 & 2.96 & 25.27 & 14.76 & 54.53 \\
$\mathrm{CH}_{4}$ & 0.24 & 0.26 & 1.33 & 0.43 & 0.27 \\
$\mathrm{H}_{2} \mathrm{O}$ & 7.98 & 9.31 & 2.79 & 2.93 & 5.45 \\
$\mathrm{CO}$ & 14.63 & 2.13 & 31.92 & 11.97 & 3.99 \\
$\mathrm{CO}_{2}$ & 1.33 & 0.67 & 2.53 & 0.93 & 0.80 \\
\hline
\end{tabular}

Some effects of air exposure on un-treated POCO are shown by Table 2. This sample was heated from 50 to $1500^{\circ} \mathrm{C}$ and maintained at this temperature for $1.5 \mathrm{~h}$, allowed to ccol in vacuum, and subjected to the same heat treatment a second time. Subsequent identical thermal desorption cycles were performed on the sample after $3 \mathrm{~h}, 8 \mathrm{~h}$ and 22 days of air exposure. The total amounts of the gases evolved during these subsequent outgassing cycles are shown, normalized to the first outgassing cycle. After $8 \mathrm{~h}$ air exposure, outgassing from the sample 
increased about an order of magnitude and after 3 weeks of air exposure, the quantities of the desorbed gases were approximately equal to those desorbed from the sample in its 'as received' condition.

Table 2. Ratio of the amount of gas desorbed during a desorption cycle to the amount desorbed initially by an 'as received' POCO sample.

\begin{tabular}{|c|c|c|c|c|c|}
\hline Gas & $\begin{array}{l}\text { as re- } \\
\text { received }\end{array}$ & $\begin{array}{l}\text { 2nd desorp- } \\
\text { tion cycle }\end{array}$ & $\begin{array}{l}\quad \text { after } \\
3 \text { hour air } \\
\text { exposure }\end{array}$ & $\begin{array}{c}\text { after } \\
8 \text { hour air } \\
\text { exposure. }\end{array}$ & $\begin{array}{c}\text { afier } \\
22 \text { day air } \\
\text { exposure. }\end{array}$ \\
\hline $\mathrm{H}_{2}$ & 1.0 & $3.2 \times 10^{-3}$ & $4.3 \times 10^{-3}$ & $1.5 \times 10^{-2}$ & 1.4 \\
\hline $\mathrm{CH}_{4}$ & 1.0 & $8.5 \times 10^{-4}$ & $1.7 \times 10^{-3}$ & $6.2 \times 10^{-3}$ & 1.7 \\
\hline $\mathrm{H}_{2} \mathrm{O}$ & 1.0 & $1.2 \times 10^{-4}$ & $7.4 \times 10^{-4}$ & $2.0 \times 10^{-3}$ & $2.6 \times 10^{-1}$ \\
\hline $\mathrm{CO}$ & 1.0 & $3.1 \times 10^{-4}$ & $7.4 \times 10^{-4}$ & $2.5 \times 10^{-3}$ & $5.6 \times 10^{-1}$ \\
\hline $\mathrm{CO}_{2}$ & 1.0 & $1.7 \times 10$ & $7.1 \times 10$ & $2.2 \times 10$ & 1.3 \\
\hline
\end{tabular}

Graphite outgassing reflects both physical and chemical phenomena associated with pore structure and surface area, reactions of impurities and their aggregation, reactions of evolving gases with graphite and its impurities, and the decomposition of surface compounds of graphite. Inorganic impurities may be introduced in the raw material or in the processing of graphite. Some processing may be less prone to the incorporation of impurities (e.g.) composites formed from synthesized pure organic compounds). During the graphitization process, some impurities such as titanium and vanadium form stable carbides and remain in the product material. Other impurities are volatilized but re-condense in the internal graphite pore structure as the graphitization furnace is cooled. These are also in the form of carbides, e.g. Fe, Si, Ca. The impurities may be aggregated or finely divided in a way that can affect the extent of their reactions with atmospheric contaminants. There are several routes for atmospheric interactions. Thus, the chemistry of various types of impurities results in difierent but understandable outgassing behavior that reflect the storage history and the pore structure of the graphite.

Chemical reactions that can occur as the result of calcium, iron and silicon impurities with estimates of approximate temperatures are shown as schematic flow diagrams: 


$$
\begin{gathered}
\mathrm{CaC}_{2} \underset{\mathrm{Air}}{\longrightarrow} \mathrm{Ca}(\mathrm{OH})_{2} \underset{200-}{2000^{\circ} \mathrm{C}} \mathrm{CaO}+\mathrm{H}_{2} \mathrm{O} \\
\mathrm{CaCO}_{3} \underset{300}{\longrightarrow} \underset{400^{\circ} \mathrm{C}}{\longrightarrow} \mathrm{CaO}+\mathrm{CO}_{2}
\end{gathered}
$$

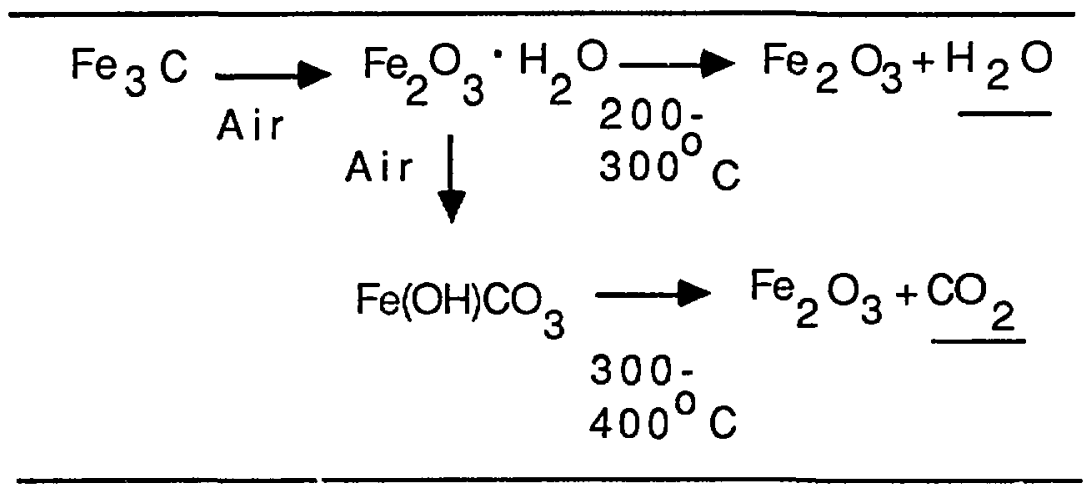

$$
\mathrm{Fe}_{2} \mathrm{O}_{3}+\underset{>700^{\circ} \mathrm{C}}{\mathrm{C}} \mathrm{Fe}+\underline{\mathrm{CO}}
$$

$$
\underset{\mathrm{Air}}{\longrightarrow} \underset{+}{\longrightarrow} \underset{(\mathrm{Si}-\mathrm{OH})}{\longrightarrow}(\mathrm{Si}=\mathrm{O})+\mathrm{H}_{2} \mathrm{O}
$$

The observed gaseous species are underlined. All reactions involving $\mathrm{CaO}$ are reversible. $\mathrm{CaCO}_{3}$ is usually finely dispersed in the bulk. With $\mathrm{Fe}_{3} \mathrm{C}$, the same impurity may account for several outgassing products. Many of these reactions are reversible when the graphite is re-exposed to air after outgassing. At temperatures above $700^{\circ} \mathrm{C}$, Ni catalyzes the evolution of $\mathrm{H}_{2}$, and the water vapor reacts with the graphite. SiO is formed above $1400^{\circ} \mathrm{C}$. Mass 28 (CO) is typically evolved following an air exposure as a result of decomposing oxides of graphite and as a result of a reaction product of iron oxide with graphite.

The values of the most abundant impurities found in some of the types of graphites used in these studies are shown in Table 3. These data were taken by Inductively Coupled Plasma (ICP) spectroscopy [7]. The values 
seen in the columns under POCO-1 and POCO-2 are from two samples from the same billet and are an example of the variation in impuritiy levels from the same billet. The values seen in the three columns under the Stackpole heading are from three billets of the same type material. Large variations were observed in some of the impurities in these samples. In spite of the complexities resulting from the structure of the graphites, the distribution of impurities and the chemical reactions involved, a relationship is seen between the amounts of trace impurities shown in Table 3 and the amounts of gases evolved from the samples in Tabie 1. By decreasing the trace impurity levels, outgassing should be reduced.

Table 3. The most abundant solid impurities, in ppm, found in two POCO samples from the same billet, three Stackpole samples from different billets and a carbon-carbon composite sample utilizing ICP spectroscopy.

(ppm)

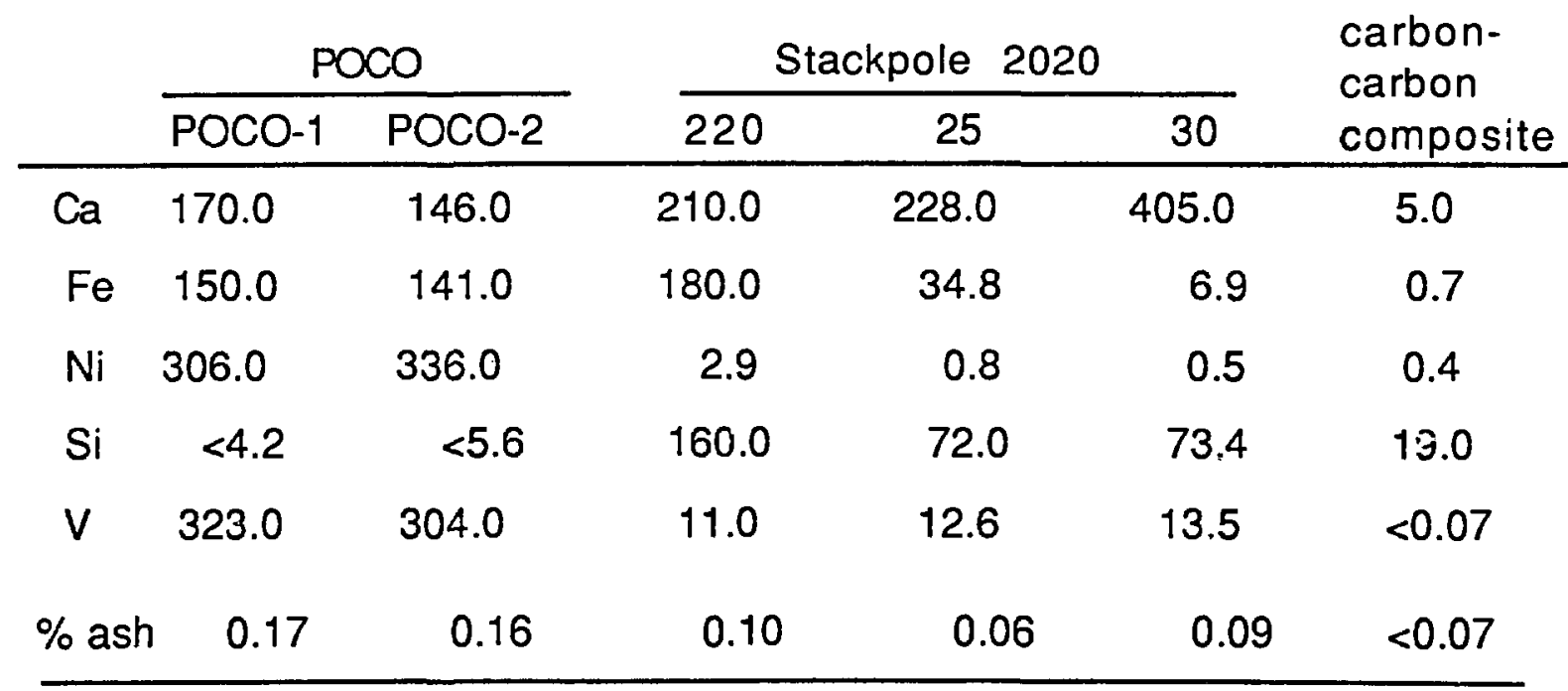

The purification process for these specimens consisted of heating the graphite to $2800^{\circ} \mathrm{C}$ in an $\mathrm{Ar}$ atmosphere for $30 \mathrm{~min}$. After this treatment, all the impurities shown in Table 3, except vanadium were reduced. The total ash content for POCO was reduced from 1700 to 350 parts-per-million with similar values for Stackpole materials. Table 4 shows the improvement in the outgassing behavior of a POCO and Stackpole sample after purification. These samples were thermally desorbed prior to purification and the amounts of gases evolved in $\mathrm{Pa}-\mathrm{llg}$ are shown. They were purified as explained above, and after 6 weeks 
exposure to the atmosphere, they were again thermally desorbed. Finally, after an additional 5 days air exposure for POCO and 11 days for Stackpole they were subjected to an additional thermal desorption cycle.

Table 4. Total gases desorbed from a POCO and a Stackpole sample, com paring values obtained from the "as received" samples to those observed after purification.

\begin{tabular}{|c|c|c|c|c|c|c|}
\hline \multirow[b]{4}{*}{ mass } & \multicolumn{5}{|c|}{$(\mathrm{Pa}-1 / \mathrm{g})$} & \\
\hline & \multirow[b]{3}{*}{$\begin{array}{l}\text { as re- } \\
\text { ceived }\end{array}$} & $\mathrm{POCO}$ & & \multirow[b]{3}{*}{$\begin{array}{l}\text { as re- } \\
\text { ceived }\end{array}$} & \multirow{2}{*}{\multicolumn{2}{|c|}{$\frac{\text { Stackpole }}{\text { purified }}$}} \\
\hline & & \multicolumn{2}{|c|}{ purified } & & & \\
\hline & & $\begin{array}{l}6 \text { week air } \\
\text { exposure }\end{array}$ & $\begin{array}{l}7 \text { week air } \\
\text { exposure }\end{array}$ & & $\begin{array}{c}6 \text { week air } \\
\text { exposure }\end{array}$ & $\begin{array}{l}8 \text { week air } \\
\text { exposure }\end{array}$ \\
\hline 2 & 19.95 & 3.59 & 2.79 & 25.27 & 5.32 & 2.00 \\
\hline 15 & 2.39 & 0.11 & 0.09 & 1.33 & 0.13 & 0.65 \\
\hline 18 & 7.98 & 0.73 & 1.33 & 2.79 & 0.80 & 1.22 \\
\hline 28 & 14.63 & 3.99 & 4.26 & 3.99 & 1.33 & 1.46 \\
\hline
\end{tabular}

In order to observe any changes in the outgassing of graphite due to exposure to plasma, an un-treated and a purified POCO sample were exposed to plasma. Outgassing data before and after exposure in an ECH deuterium plasma to a fluence of $10^{20}$ particles $/ \mathrm{cm}^{2}$ at $150 \mathrm{eV}$ are shown in Table 5. In each case, the thermal desorption cycle was identical: the sample was heated linearly from 50 to $1500^{\circ} \mathrm{C}$ for $1 \mathrm{~h}$, and held at this temperature for $1.5 \mathrm{~h}$. In each case the sample received approximately $1 \mathrm{~h}$ of atmospheric exposure following the plasma exposure. The amount of water evolved during thermal desorption of the un-treated POCO sample was observed to increase by a factor of 6 after plasma exposure, while the increase in the purified sample is only a factor of 2 .

Fig. 1 shows the behavior of water desorption from the un-treated sample before and after plasma exposure as functions of time and temperature. Before plasma exposure, a large portion of the water is 
desorbed between 50 and $600^{\circ} \mathrm{C}$; after the exposure, relatively little is desorbed below $600^{\circ} \mathrm{C}$. Fig. 2 shows the partial pressure of water desorbed from the purified sample before and after plasma exposure; these curves are similar except that two peaks occur after plasma exposure between 50 and $600^{\circ} \mathrm{C}$.

Table 5. Total gases desorbed from POCO un-treated sample and from purified sample before and after plasma exposure

\begin{tabular}{|c|c|c|c|c|}
\hline \multirow[b]{3}{*}{ Mass } & \multirow{2}{*}{\multicolumn{2}{|c|}{$(\mathrm{Pa}-1 / \mathrm{g})$}} & \multirow{2}{*}{\multicolumn{2}{|c|}{ Purified }} \\
\hline & & & & \\
\hline & $\begin{array}{c}\text { Before plasma } \\
\text { exposure }\end{array}$ & $\begin{array}{c}\text { After plasma } \\
\text { exposure }\end{array}$ & $\begin{array}{c}\text { Before plasma } \\
\text { exposure }\end{array}$ & $\begin{array}{c}\text { After plasma } \\
\text { exposure }\end{array}$ \\
\hline 2 & $1.7 \times 10^{-2}$ & $2.7 \times 10^{-3}$ & $2.7 \times 10^{-3}$ & $1.6 \times 10^{-3}$ \\
\hline 3 & & $6.3 \times 10^{-5}$ & $<1.0 \times 10^{-7}$ & $6.0 \times 10^{-5}$ \\
\hline 4 & & $8.0 \times 10^{-5}$ & $<1.0 \times 10^{-7}$ & $1.3 \times 10^{-5}$ \\
\hline 17 & $2.8 \times 10^{-3}$ & $1.6 \times 10^{-2}$ & $5.3 \times 10^{-4}$ & $9.3 \times 10^{-4}$ \\
\hline 18 & $9.3 \times 10^{-3}$ & $5.3 \times 10^{-2}$ & $1.7 \times 10^{-3}$ & $3.7 \times 10^{-3}$ \\
\hline 19 & & $1.2 \times 10^{-3}$ & $1.6 \times 10^{-7}$ & $8.0 \times 10^{-5}$ \\
\hline 20 & & $2.1 \times 10^{-4}$ & $4.0 \times 10^{-7}$ & $1.3 \times 10^{-5}$ \\
\hline 28 & $1.6 \times 10^{-2}$ & $2.9 \times 10^{-3}$ & $1.4 \times 10^{-3}$ & $2.7 \times 10^{-3}$ \\
\hline
\end{tabular}

Large quantities of hydrogen are retained in the near surface region of graphite. Isotopic exchange may occur in this region when a different isotope is implanted and the exchange rate increases as it reaches saturation [8]. In the case of the unpurified sample, the hydrogen that was exchanged by deuterium could react with oxides of the trace impurities in accordance with the chemical reactions described earlier to yield the increased quantities of water observed during subsequent thermal desorption. We calculate the equilibrium constant, $K_{p}$, for the 
reaction:

$$
1 / 2 \mathrm{H}_{2} \mathrm{O}+1 / 2 \mathrm{D}_{2} \mathrm{O}=\mathrm{HDO}
$$

The free energy change, $\triangle \mathrm{G}$, for the reaction is found to be -0.3895 $\mathrm{kcal} / \mathrm{mole} \mathrm{HDO}$ at $298^{\circ} \mathrm{K}$ and $-2.4655 \mathrm{kcal} / \mathrm{mole} \mathrm{HDO}$ at $1800^{\circ} \mathrm{K}$ [9]. These values correspond to equilibrium constants of 1.93 and 1.99 respectively as calculated from the expression:

$$
\Delta G=-R T \ln K_{p}
$$

where $p$ is the pressure of the subcripted gas species.

We may compare this value with that determined by mass action law from the experimental data in table 5. From the experimental data, $K_{p}=$ 0.38 for the purified sample, and 0.36 for the un-treated sample. Because of a calculated value of 1.99 at $1800^{\circ} \mathrm{K}$, this implies that these specimens are not in isotopic equilibrium. The apparent enhanced protium oxide concentration $\left(\mathrm{H}_{2} \mathrm{O}\right)$ may reflect a reaction with moist air following the plasma exposure or the outgassing of surface species without equilibrating.

\section{Conclusions}

Un-treated graphite that has been outgassed at $1500^{\circ} \mathrm{C}$ may be exposed to atmosphere for $8 \mathrm{hrs}$ without exhibiting evidence of a significant increase in the absorption of air, but it reverts to its original, 'as received' condition within 3 weeks. However, up to an order of magnitude less water vapor was desorbed from graphite that was subjected to a purification process. This process removes much of the trace impurities which react with atmospheric gases and hydrogen and are responsible for the outgassing characteristics of the un-treated sample. The usual practice of outgassing graphite at $150^{\circ} \mathrm{C}$ before its use in fusion devices does not remove these impurities. Trace impurities are also responsible for the increase in water production when graphite is exposed to plasma.

\section{Acknowledgments}

The authors thank T.F. Rayburn for his technical assistance during the experiments. 


\section{References}

1. H. F. Dylla et al., J. Nucl. Mater. $128 \& 129,861$ (1984).

2. M. Huguet et al., in Proceedings of the 11th Symposium on Fusion Engineering (IEEE Service Center, Piscataway, N.J. (1986), 1238 (1986).

3. L. De Kock et al., J. Nucl. Mater. 145-147, 26 (1987).

4. J. E. Simpkins and P. K. Mioduszewski, Rev. Sci. Instrum. 59, 276 (1988).

5. A. E. Pontau and D. H. Morse, J. Nucl. Mater, 141-143, 124 (1986).

6. T. Uckan, Rev. Sci. Instrum. 58, 17 (1987).

7. S. Greenfield, H. McD. McGeeachin and P. B. Smith, Palanta 23, 1 (1976).

8. K. L. Wilson and W. L. Hsu, J. Nucl. Mater. 145-147, 121 (1987).

9. JANAF Thermochemical Tables, Dow Chemical Company, Midland, MI (1979). 


\section{FIGURE CAPTIONS}

Fig. 1. The partial pressure of water vapor as a function of time from thermal desorption measurements on un-treated POCO (a) before and (b) after plasma exposure. The variation of sample temperature with time is also shown (dashed curve).

Fig. 2. The partial pressure of water vapor as a function of time from thermal desorption measurements on purified POCO (a) before and (b) after plasma exposure. The variation of sample temperature with time is also shown (dashed curve). 
ORNL-OWG 88-2694R FED

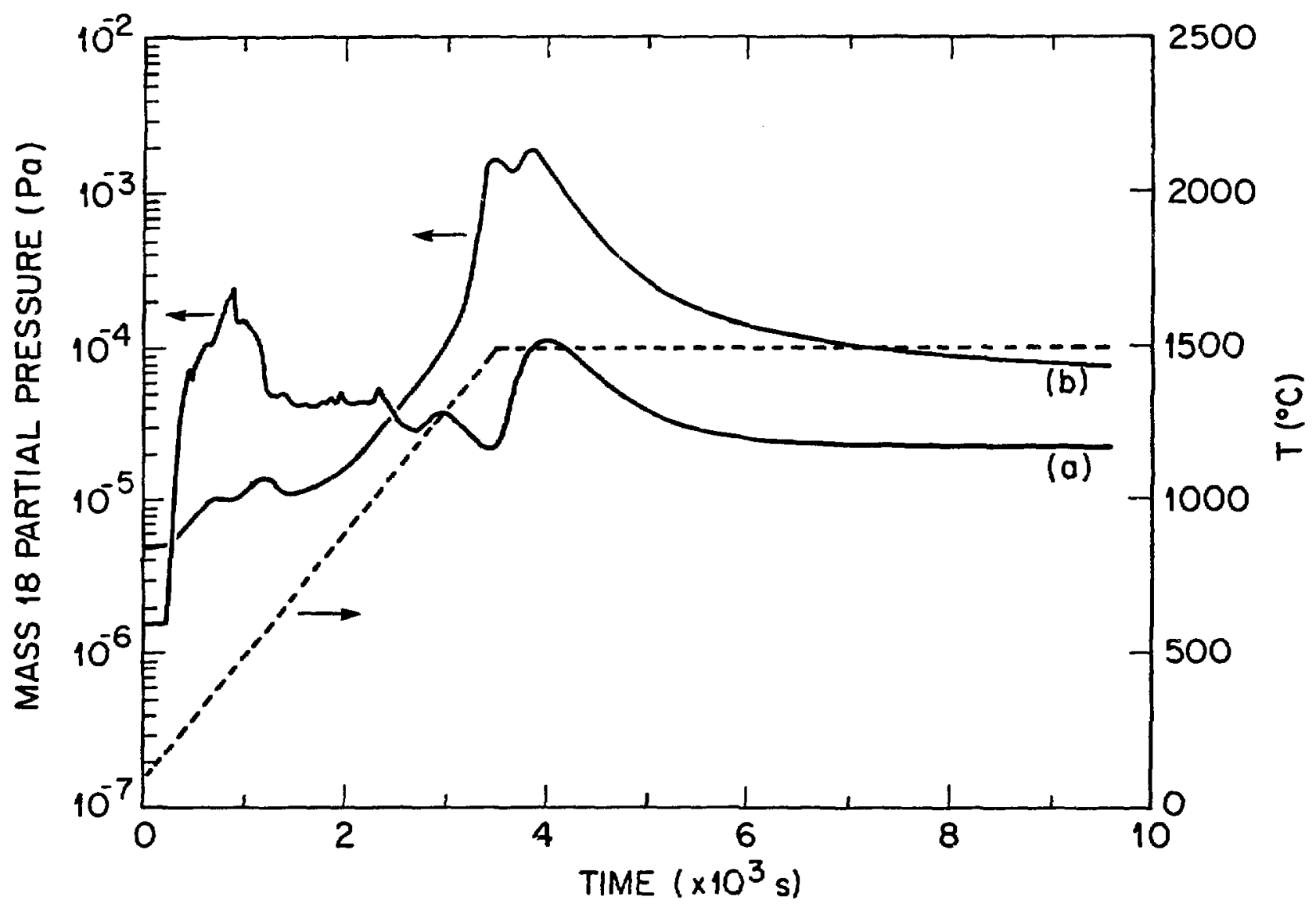




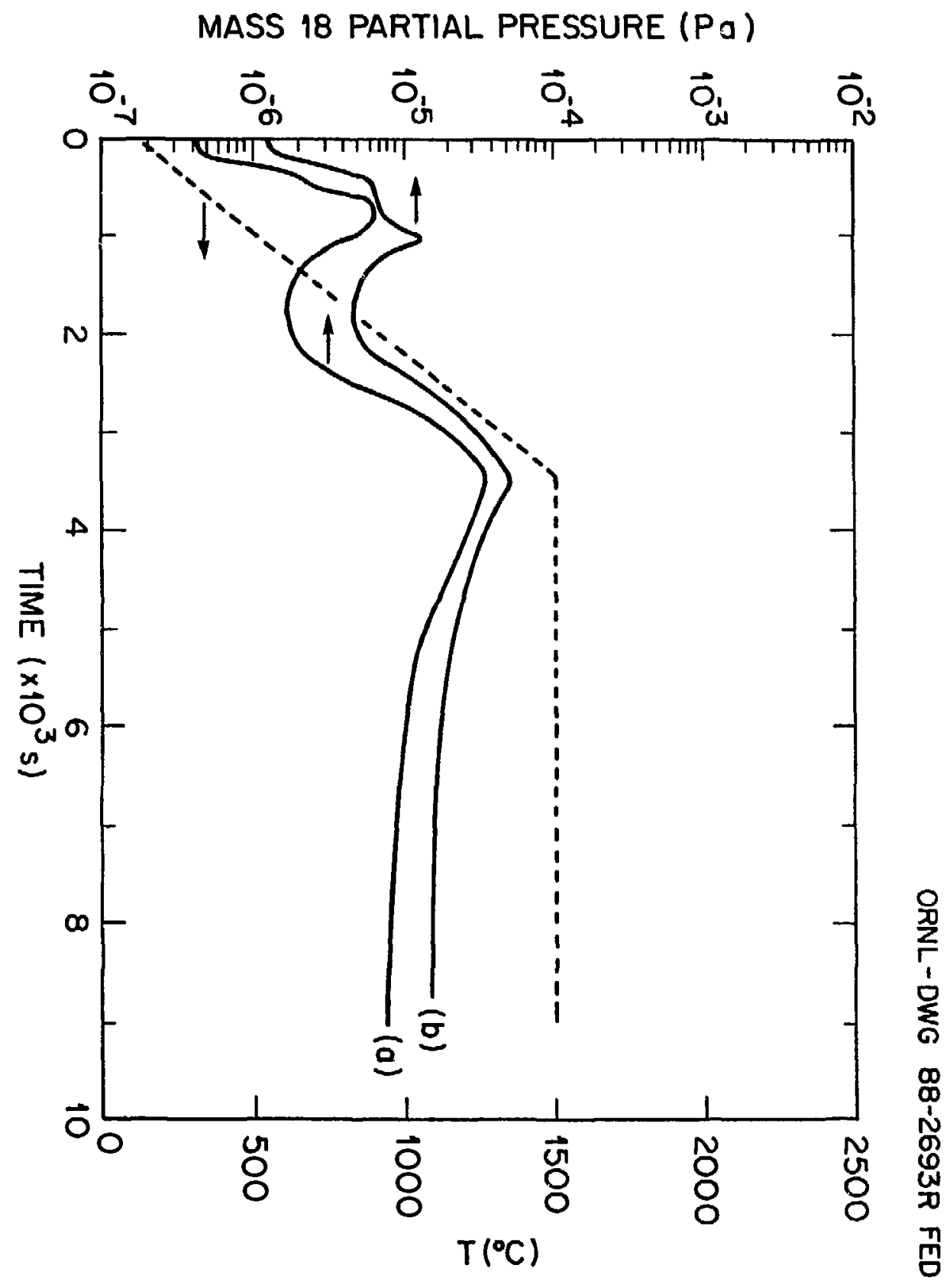

